\title{
A Study on Improving the Mechanical Behaviors of the Pultruded GFRP Composite Material Members
}

\author{
Yeou-Fong Li ${ }^{1, *}$, Tseng-Hsing $\mathrm{Hsu}^{2}$ and Fu-Chr Hsieh ${ }^{1}$ \\ 1 Department of Civil Engineering, National Taipei University of Technology, Taipei 10608, Taiwan; \\ notonlyfly@hotmail.com \\ 2 Department of Civil Engineering, Chung-Hua University, Hsinchu 30012, Taiwan; thsu@chu.edu.tw \\ * Correspondence: yfli@mail.ntut.edu.tw
}

Received: 26 December 2018; Accepted: 15 January 2019; Published: 22 January 2019

\begin{abstract}
This study focuses on improving the mechanical behaviors of pultruded glass fiber-reinforced polymers (GFRP) composite material. A combined GFRP member was prepared by the insertion of a second GFRP tube inside the prototype GFRP member and then filling the compartment with epoxy resin mortar to combine both members. Analysis of the combined member was performed to consider improvement of the stiffness and strength of the material to meet design requirements. Four different types of GFRP deck specimens and five different types of GFRP beam specimens were investigated by performing the three-point bending test to obtain their ultimate strength, ultimate displacement, stiffness, and corresponding failure modes. Observations from the experiment showed that infilling the rectangular GFRP tube member can effectively increase the GFRP specimen's stiffness and ultimate strength. Finally, the Euler beam and Timoshenko beam theories combined with the transformed section method were used to obtain the stiffness of the combined GFRP members, and then compare those stiffness with the experimental results.
\end{abstract}

Keywords: glass fiber reinforced plastics; epoxy resin mortar; three-point bending test; low carbon emission; low life cycle cost

\section{Introduction}

Reinforced concrete infrastructures usually are subject to deterioration or damage caused by environmental and artificial factors, such as concrete material carbonation, chloride attack, huge temperature variation, earthquakes, fire attack, and overloading etc. In coastal areas, the atmosphere contains chlorine which corrodes steel reinforcement in reinforced concrete bridges. As a result, the loading capacities of the deteriorated reinforced concrete bridges often are not sufficient to carry the loads imposed upon them. Fiber-reinforced polymer (FRP) composite materials exhibit the characteristics of low carbon emission, low thermal conductivity, lightweight, anti-corrosion, excellent weather resistance, high strength-to-weight ratio, and high modulus of elasticity and having great design flexibility. Furthermore, FRP composite materials can offer a longer maintenance-free service life and low life-cycle cost; and also FRP composite materials can be recyclable and reusable, therefore is a sustainable material for civil engineering usage.

Concrete has been identified as a prime contributor of the greenhouse gas carbon dioxide in the atmosphere and sustainable materials are now more important than ever to reduce carbon emissions, especially in civil engineering infrastructure. Since FRP accounts for low carbon emissions and is a sustainable material. Li et al. [1] calculated that an $8 \mathrm{~m}$ long GFRP pedestrian bridge reduced total carbon emission about $43 \%$ and $19 \%$ compared to a similar reinforced concrete pedestrian bridge or a steel pedestrian bridge, respectively. Zhang et al. [2] showed that for a GFRP composite superstructure 
of a $12 \mathrm{~m}$ long road bridge, carbon emissions were reduced by $48 \%$ and $57 \%$ when compared with a concrete bridge and steel bridge designed for the same use.

Different forms of FRP composite materials have been used for research and application purposes in civil engineering since the 1980s. Hollaway [3] discussed the development of the advanced polymer composite material applications in buildings and civil/structural infrastructure over the past three to four decades. The material has extraordinary mechanical and important in-service properties which, when combined with other materials, improve the stiffness/strength and durability, enhance the whole-life cycle cost, and reduce the environmental impact.

In the last few decades, the research and development of FRP composite materials in the United States, Canada, United Kingdom, Japan, Taiwan, and many countries have focused on the applications of FRP composite materials in civil engineering. In addition to related research on FRP composite beams, many researchers have also studied the manufacturing process, which contains modular components, mechanical infilling and hybrid fiber components.

In the last few decades, a series of experimental and numerical research works on GFRP composite material decks have been discussed, as follows. The experimental fatigue and strength test, and finite-element simulation were performed for an all-composite bridge deck [4-6]. In the meantime, GFRP decks filled with foam concrete were investigated using three-point bending, four-point bending, and finite element analysis software [7-9]. The failure modes of pultruded hollow GFRP tubes of squared cross section were also investigated using the three-point bending test, including dynamic load and static load under cyclic loading $[10,11]$. The structural behavior of the hybrid FRP beam consisting of carbon/glass fibers were investigated using experimental and analytical approaches to find the optimal design of hybrid beams [12]. A honeycomb lattice in the interlayer of the GFRP deck was investigated using a four-point bending test in order to find the shear strength/resistance of the deck under lateral loading. [13].

The comparison of the strength, stiffness and other qualities of GFRP with different materials, such as concrete, steel and aluminum, to manufacture composite decks were discussed by many researchers. Fam and Honickman [14] used a pultruded hat-shape GFRP trapezoidal section combined with a flat GFRP plate and a concrete slab cast above the plate. The new box girder was shown to have equivalent flexural strength to similar sized, heavily reinforced concrete box girders. Ji et al. $[15,16]$ used GFRP composite material and aluminum to form a hybrid trapezoidal composite sandwich bridge deck. They also designed and tested a GFRP corrugated-core sandwich in which aluminum sheet was used as the composite material. Lombardi and Liu [17] also made a steel and GFRP hybrid bridge deck, the upper flange of which was made of steel and the middle web of honeycomb GFRP profile. The honeycomb GFRP decks had a superior bending and shear stiffness. Zuo et al. [18] proposed a hybrid composite deck; the GFRP plate is placed at the tension side of the deck and the concrete at the compressive side in order to understand the flexural performance of proposed hybrid decks.

In the design and construction of the pedestrian GFRP composite material bridge by Li et al. [19], the bridge design was controlled by the deflection of the girder instead of the strength. Sometimes, the factor of safety of the main girder reaches 20 , and it is not an economical design. The major goals of this paper are to improve the stiffness of GFRP members by increasing the moment of inertia, and also improve the strength of GFRP members. Two attempts employed to achieve the above goals are: (1) inserting a rectangular GFRP tube into the compartments of the GFRP members; (2) filling some hollow compartments with epoxy resin mortar. The three-point bending test was used to understand the impact on the stiffness and the failure mode of the combined GFRP members.

\section{Glass Fiber-Reinforced Polymer (GFRP) Deck and Beam Members}

Pultrusion is a method of producing GFRP linear profiles. A traction device was employed to pull the fiber yarns which were impregnated in resin and then cured by a heated molding die. The pultruded GFRP members used in this paper include the matrix which is thermosetting unsaturated polyester resin and the fiber, which is E-glass fiber. The E-glass fiber and unsaturated polyester resin 
contents are $55 \%$ and $45 \%$, respectively. Pultrusion of the GFRP member was done in a single fiber direction. When subject to loading, the GFRP member becomes prone to failure/rupture along the fiber direction. Inserting another rectangular GFRP tube can increase the strength and stiffness, and also can change the failure mode and failure location. The GFRP members of the composite section were bonded by epoxy resin and the bonding strength of the epoxy resin is $3.2 \mathrm{MPa}$. To avoid excessive deflection of the beam, epoxy resin mortar was filled inside the component to improve its overall stiffness and reduce the amount of deformation. The GFRP members were loaded at its midpoint in a three-point bending experiment; then the displacements and corresponding loads were measured.

The elastic modulus, Poisson's ratio and shear modulus of GFRP composite and epoxy resin mortar are shown in Table 1. The material properties of GFRP were tested by SGS Taiwan branch according to ASTM standards, and the material properties of epoxy mortar were tested by the authors at National Taipei University of Technology. Regarding the epoxy mortar, the Young's modulus was obtained according the ASTM C873-99 test method. Since the epoxy mortar is isotropic material, the shear modulus of epoxy mortar was calculated from Equation (3).

Table 1. Material properties of the glass fiber-reinforced polymer (GFRP) composite materials and epoxy mortar.

\begin{tabular}{cccc}
\hline Material & Young's Modulus, & Poisson Ratio, & Shear Modulus, \\
E [GPa] & $\boldsymbol{v}$ & G [GPa] \\
\hline GFRP & 21 & 0.33 & 7.89 \\
Epoxy mortar & 4.8 & 0.31 & 1.8 \\
\hline
\end{tabular}

In this paper, two groups of GFRP members were proposed. The first group is GFRP decks with inserted rectangular GFRP tube, and the cross-sections are shown in Figure 1. The second group is the GFRP beams with inserted another rectangular GFRP tube, the cross sections of the members are shown in Figure 2. The GFRP members of the composite section were bonded by epoxy resin, as shown in Figures 1c and 2c. Some GFRP members were filled with epoxy resin mortar in some compartments to form a combined GFRP member.

Specimens were named or denoted using letters and/or combinations of letters and numbers. The deck specimen is denoted as " $\mathrm{A}$ "; two hollow-rectangular GFRP tubes were inserted into each of the compartments of the deck and are denoted as "AT". "ATE1" and "ATE2" are the extended versions of specimen "AT" by inserting epoxy resin mortar mixture in different compartments. The beam specimen is denoted as " $\mathrm{B}$ "; specimen "BE" was filled with epoxy resin mortar inside the GFRP beam; "BR" had another two hollow-rectangular GFRP tubes inserted inside it; "BRE1" and "BRE2" are the extended version of specimen "BR" by inserting epoxy resin mortar mixture in different compartments also. The cross-sectional views of the GFRP deck and beam specimens are shown in Table 2.

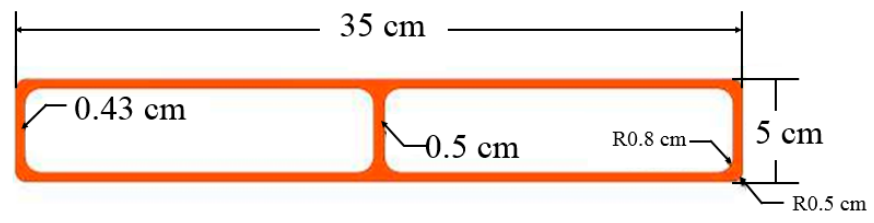

(a) Deck member section

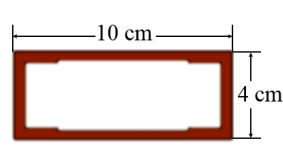

(b) Tube member section

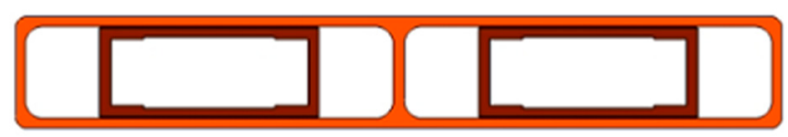

(c) Combined deck member section

Figure 1. Illustration of the deck and tube member sections. 


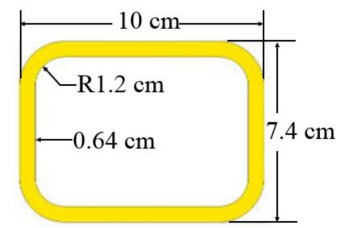

(a) Beam member section

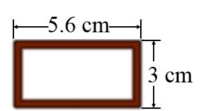

(b) Tube member section

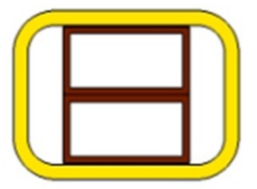

(c) Combined beam member section

Figure 2. Illustration of the beam and tube member sections.

Table 2. The cross-sectional views of the GFRP deck and beam specimens.

\begin{tabular}{|c|c|c|c|}
\hline Specimen & Cross-Sectional View & Specimen & Cross-Sectional View \\
\hline A & & B & \\
\hline AT & & BR & \\
\hline ATE1 & Q 198 & $\mathrm{BE}$ & \\
\hline ATE2 & & BRE1 & \\
\hline & & BRE2 & \\
\hline
\end{tabular}

\section{Experimental Setups}

The three-point bending test was used to obtain the load-displacement relationships of GFRP decks and beams. The net span is $90 \mathrm{~cm}$ of the three-point bending test for the GFRP specimen, as illustrated in Figure 3. A total of four GFRP decks and five GFRP beam specimens were studied using the three-point bending test at a loading rate of $5 \mathrm{kN} / \mathrm{min}$. The specimens used in the three-point bending test were $1 \mathrm{~m}$ length ( $90 \mathrm{~cm}$ span) of GFRP deck and beam members, which were varied by inserting another GFRP rectangular tube inside the member and filling in epoxy resin mortar, as shown in Table 2.

The load cell (WF 17120, Wykeham Farrance, Milan, Italy) with 50 tons capacity was used to measure the loading applied on the specimen. The dial gauge (DDP-30A, Tokyo Sokki Kenkyujo, Tokyo, Japan) was used to measure the displacements of the specimen. The high-precision data logger (KL-10, Geomaster Group, Tianjin, China) was used to record the force and displacement data, and a 1 data/second sampling rate was set to record the force-displacement data. 


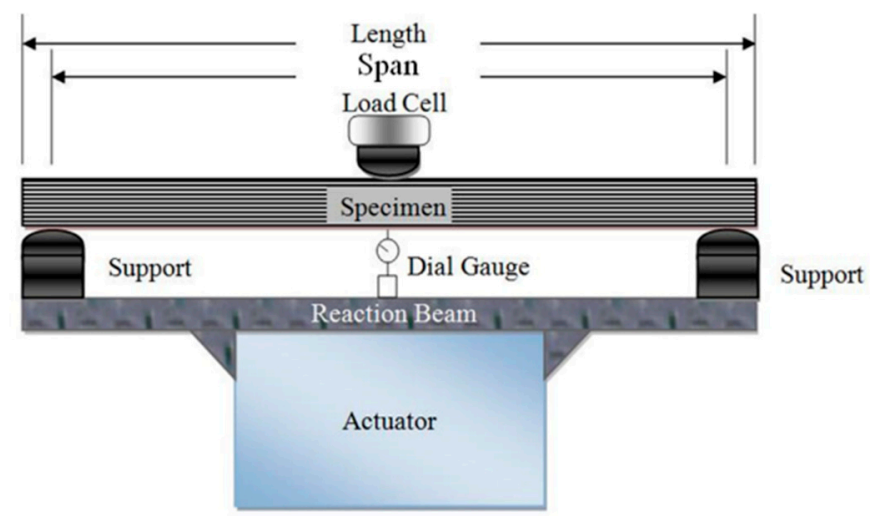

Figure 3. Illustration of the three-point bending test.

\section{Three-Point Bending Test Result}

The combined members have complex cross-sections and combined with two different materials, GFRP and epoxy mortar. Sometimes, the interface between GFRP and epoxy mortar might debone under loading. Therefore, a series of three-point bending test were carried out to observe the failure modes of different combined member beams.

\subsection{Experimental Observation of Deck Specimens}

This research involved mainly the prototype members, the cross-section was varied by inserting another GFRP rectangular tube inside the member and filling in epoxy resin mortar as shown in Table 2. The results of testing were as follows:

- Specimen A

A large cracking sound was heard when specimen A was subjected to the load of $21.62 \mathrm{kN}$ and the specimen cracked at the middle point of the loading location during the test. The maximum load of $26.98 \mathrm{kN}$ corresponded to measured center displacements of $1.58 \mathrm{~cm}$. The failure mode of specimen A, shown in Table 3, is at the loading location of the top flange. The force-displacement relationship of specimen A is shown in Figure 4.

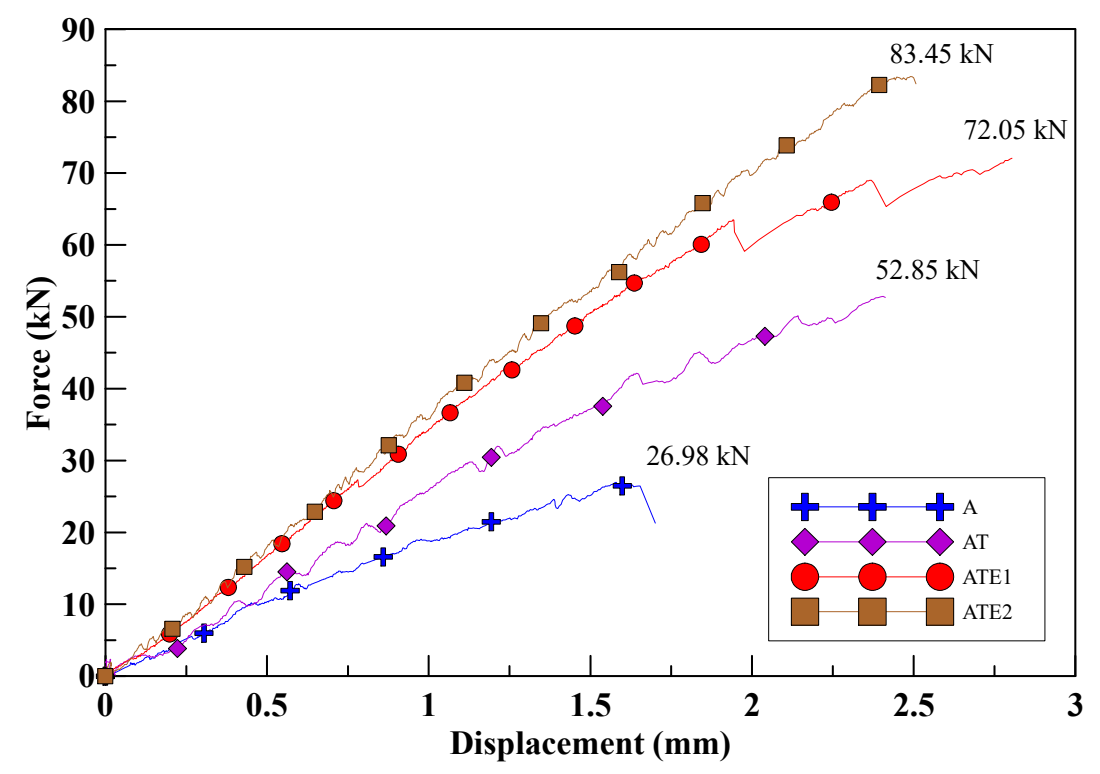

Figure 4. The comparisons of the force-displacement relationships of all GFRP deck specimens. 
Table 3. The failure location and corresponding photos of GFRP deck specimens.

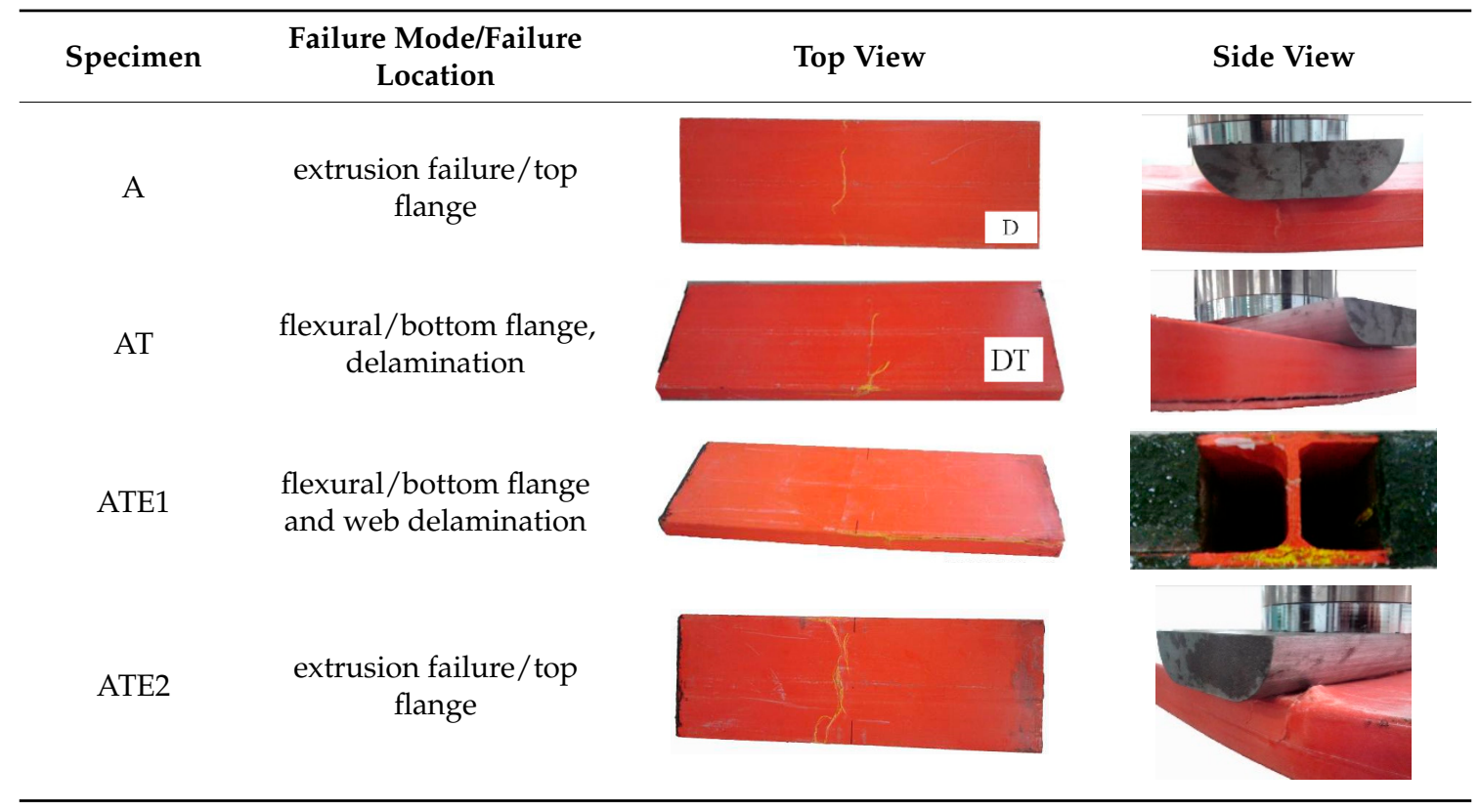

- Specimen AT

When the specimen AT was loaded to $42.13 \mathrm{kN}$, local buckling phenomena occurred on the flanges and the specimen cracked in the middle point of the loading location. Failure occurred when the applied load reached the value of $52.85 \mathrm{kN}$ and the corresponding displacement was $2.41 \mathrm{~cm}$. It was observed that at some point before failure, the deck and tube tended to separate along the interface of bondage. This was evidenced from a continuous stripping sound and finally became visually apparent. Yet other important observations were the delamination of specimen fibers and massive damages along the corners of the members as shown in Table 3. The applied load could not be passed evenly to the tension side of the deck thus causing buckling at the corners. The force-displacement relationship is shown in Figure 4.

\section{- Specimen ATE1}

When the load reached $63.47 \mathrm{kN}$, the interface between the deck member and the inserted tube began to separate and the inner webs broke in the region where they intersect the flanges. This was accompanied by continuous stripping sounds indicating that the phenomena is propagating along the specimen. As the specimen was continuously loaded to $69.01 \mathrm{kN}$; there were load crumble sounds indicating the fracture of the epoxy resin mortar inside the specimen; and the outer profiles of the specimen at this stage was visually intact. As the loading was continuously applied until the specimen failed at a load of $72.05 \mathrm{kN}$, significant damage occurred at the corners and along the interface between inner webs and flanges as shown in Table 3. The force-displacement relationship for specimen ATE1 is shown in Figure 4.

\section{- Specimen ATE2}

To improve the failure mode, and upgrade the stiffness and ultimate load of the first configuration, the second configuration was filled with epoxy resin mortar in the outer compartments. When the specimen ATE2 was loaded up to $63.0 \mathrm{kN}$, the webs began to fail by local buckling. At an ultimate force load of $83.45 \mathrm{kN}$, the corresponding displacement was $2.45 \mathrm{~cm}$; then, it was accompanied by the similar high frequency sound at ultimate failure when the specimen fractured as in Table 3 . The local 
buckling was due to the force inability to be transmitted evenly to the tension side of the specimen. The force-displacement relationship of Specimen ATE2 is shown in Figure 4.

The ultimate force, ultimate displacement, initial stiffness, and the increased percentages of specimens AT, ATE1 and ATE2 in comparison with the prototype specimen A are shown in Table 4. As shown in Table 4, the ultimate force, corresponding to ultimate displacement, and initial stiffness of specimens AT, ATE1 and ATE2, significantly increased in comparison with the prototype specimen A. As shown in the experimental results, the ultimate strength and stiffness of specimen ATE1 increases $36 \%$ and $30 \%$ of the specimen AT respectively; the specimen ATE2 increases $58 \%$ and $39 \%$ of the specimen AT in ultimate strength and stiffness, respectively. The experimental results also show that the mechanical performance of the specimen ATE2 is better than the specimen ATE1, due to the confinement effect of the section. It can be concluded that filling the epoxy resin mortar inside the compartments of GFRP deck can improve the overall deck member's ultimate strength and stiffness.

Table 4. Summary of the three-point bending test results of GFRP double-compartment deck specimens.

\begin{tabular}{|c|c|c|c|}
\hline Specimen & $\begin{array}{c}P_{u}(\mathrm{kN}) / \\
(\text { Increase \%) }\end{array}$ & $\begin{array}{c}\delta_{u}(\mathrm{~cm}) / \\
(\text { Increase \%) }\end{array}$ & $\begin{array}{c}\text { Initial Stiffness, } K \\
(\mathrm{kN} / \mathrm{cm}) /(\text { Increase } \%)\end{array}$ \\
\hline $\mathrm{A}$ & 27.0/(reference) & 1.57/(reference) & 22.39/(reference) \\
\hline AT & $52.8 /(95.8)$ & $2.40 /(51.9)$ & $25.70 /(14.7)$ \\
\hline ATE1 & $72.1 /(167.0)$ & $2.80 /(77.2)$ & $33.50 /(49.6)$ \\
\hline ATE2 & $83.5 /(209.3)$ & $2.50 /(57.6)$ & $35.83 /(60.0)$ \\
\hline
\end{tabular}

\subsection{Experimental Observation of GFRP Beam}

A total of five GFRP beam specimens were studied by using the three-point bending test at a loading rate of $5 \mathrm{kN} / \mathrm{min}$. The three-point test was performed following the ASTM D790 test method [20]. In the following paragraphs, the ultimate strength, stiffness and failure modes are discussed for each specimen.

\section{- Specimen B}

For the prototype GFRP beam, it was found that when the load reached $13.46 \mathrm{kN}$, the fibers started to make some continuous cracking sounds. As the specimen reached its ultimate load of $16.56 \mathrm{kN}$ with the corresponding displacement $0.885 \mathrm{~cm}$, an audible, high-frequency sound accompanied the specimen's immediate failure as shown in Table 5 . The force-displacement relationship of specimen B is shown in Figure 5.

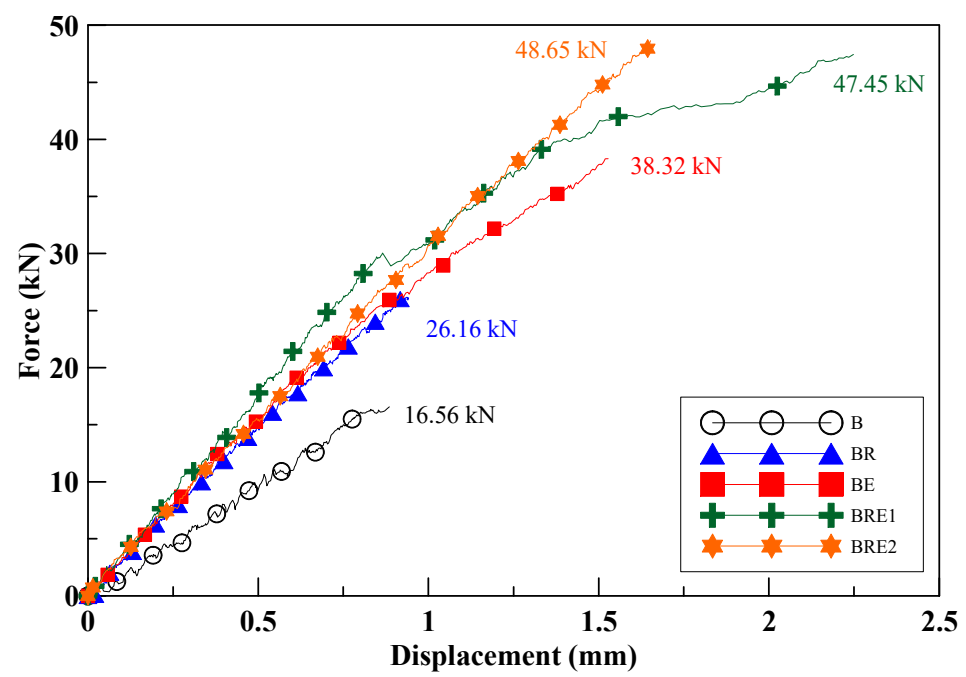

Figure 5. The comparisons of the force-displacement relationships of GFRP beam specimens. 
Table 5. The failure location and corresponding photos of GFRP beam specimens.

\begin{tabular}{ccc}
\hline Specimen & $\begin{array}{c}\text { Failure Mode/Failure } \\
\text { Location }\end{array}$ & Top View \\
extrusion \\
failure/compression side \\
(top)
\end{tabular}

- Specimen BR

It was found that when the specimen BR was loaded up to $20.91 \mathrm{kN}$, the side webs began to fail by local buckling. At an ultimate force load of $26.16 \mathrm{kN}$ with the corresponding displacement of $0.936 \mathrm{~cm}$, the component went through ultimate failure and fractured as shown in Table 5 and this was accompanied by the similar high-frequency sound. The local buckling was due to the force's inability to be transmitted evenly to the tension side of the component. As shown in Figure 5, the force-displacement relationship of specimen BR is linear.

- Specimen BE

When the specimen BE was loaded up to $30.86 \mathrm{kN}$, the side webs began to fail by local buckling. At an ultimate force load of $38.32 \mathrm{kN}$, the corresponding displacement was $1.524 \mathrm{~cm}$ and was accompanied by the high-frequency sound at ultimate failure when the component fractured, as shown in Table 5 . The specimen failed by fracturing at the tension side of the specimen. The force-displacement relationship of specimen BE is shown in Figure 5.

\section{- Specimen BRE1}

When the specimen BRE1 was loaded up to $40.12 \mathrm{kN}$, the fibers and the epoxy resin mortar started to fracture. At an ultimate force load of $47.45 \mathrm{kN}$ corresponding to a displacement of $2.248 \mathrm{~cm}$, the component reached its maximum load with a continuous splitting sound as the fibers in the tension side fractured as shown in Table 5. The experimental force-displacement relationship of specimen BRE1 was shown in Figure 5. 


\section{- Specimen BRE2}

Similarly, as the specimen BRE2 was loaded up to $39.62 \mathrm{kN}$, the fibers and the epoxy resin mortar started to fracture. The ultimate force load of $48.65 \mathrm{kN}$ corresponding to a displacement $1.652 \mathrm{~cm}$ was accompanied by a similar high-frequency sound. At this moment, the component reached its maximum load with the continuous splitting sound as the fibers in the tension side fractured, as shown in Table 5. Figure 5 shows its force-displacement relationship under the three-point bending test.

The ultimate force, corresponding ultimate displacement, initial stiffness, and their increase percentages of specimens BR, BE, BRE1 and BRE2 compared to the prototype specimen B are shown in Table 6. From the experimental results, the ultimate strength and stiffness of specimens BRE1 and BRE2 were much greater than those of specimens BR and BE. Therefore, it can be concluded that filling the beam compartments with epoxy resin mortar and adding the rectangular GFRP tube can improve the overall beam members' ultimate strength and stiffness.

Table 6. Summary of three-point bending test results of GFRP beam specimens.

\begin{tabular}{cccc}
\hline Specimen & $\begin{array}{c}\boldsymbol{P}_{\boldsymbol{u}}(\mathbf{k N}) / \\
(\text { Increase \%) }\end{array}$ & $\begin{array}{c}\delta_{\boldsymbol{u}}(\mathbf{c m}) / \\
(\text { Increase \%) }\end{array}$ & $\begin{array}{c}\text { Initial Stiffness, } \boldsymbol{K} \\
\mathbf{( k N / \mathbf { c m } ) /} \\
(\text { Increase \%) }\end{array}$ \\
\hline B & $16.6 /($ reference) & $0.885 /($ reference) & $22.02 /($ reference) \\
BR & $26.2 /(58.0)$ & $0.936 /(17.7)$ & $28.93 /(31.3)$ \\
BE & $38.3 /(131.4)$ & $1.525 /(72.3)$ & $27.94 /(26.9)$ \\
BRE1 & $47.4 /(186.5)$ & $2.248 /(154.0)$ & $34.53 /(56.8)$ \\
BRE2 & $48.6 /(193.7)$ & $1.652 /(86.7)$ & $30.66 /(39.2)$ \\
\hline
\end{tabular}

\section{Theoretical Analysis for GFRP Members}

Schniepp et al. [21] proposed that the length-depth ratio of the FRP member ranging from 6 to 10 has a great influence on the shear deformation of the FRP member. In the study, GFRP deck and beam members were analyzed using Euler beam theory and Timoshenko beam theory, respectively, due to the different length-depth ratios. Finally, the theoretical analysis and experimental results of the force-displacement relationships were compared.

\subsection{Euler Beam Theory}

For the Euler beam theory analysis, the shear effect was ignored and only the flexural deformation was considered. For uniformly cross section and constant material properties of the beam member, the midpoint displacement of the three-point bending test can be calculated from Equation (1).

$$
\delta=P \times\left(\frac{L^{3}}{48 E I}\right)
$$

In Equation (1), $P$ and $\delta$ represent the force and the midpoint displacement, respectively; $L$ is the specimen net span; and $I$ is the moment of inertia of the cross section.

\subsection{Timoshenko Beam Theory}

According to past experimental experience, a deep beam member needs to consider the shear deformation contribution. Assuming uniform cross section and the constant material properties of the beam member, the midpoint displacement of the three-point bending test can be expressed as follows by using Timoshenko beam theory analysis.

$$
\delta=P \times\left(\frac{L^{3}}{48 E I}+\frac{L}{4 k G A}\right)
$$


In the above equation, $G$ is the linear elastic shear modulus of the material, $k$ is the shear correction coefficient, and $A$ is the cross-sectional area of GFRP component. The Poisson's ratio for GFRP composite material is 0.33 . The linear elastic shear modulus $G$ can be obtained from Equation (3), where $v$ is the Poisson's ratio; and the shear correction factor $k$ can be expressed as shown in Equation (4) $[22,23]$.

$$
\begin{gathered}
G=\frac{E}{2(1+v)} \\
k=\frac{10(1+v)(1+3 m)^{2}}{\left(12+72 m+150 m^{2}+90 m^{3}\right)+v\left(11+66 m+135 m^{2}+90 m^{3}\right)+10 n^{2}\left((3+v) m+3 m^{2}\right)}
\end{gathered}
$$

where

$$
\begin{gathered}
m=\frac{b t_{1}}{b t} \\
n=\frac{b}{h}
\end{gathered}
$$

The dimension notations of the hollow section beam $t_{1}, t, b$ and $h$ are shown in Figure 6.

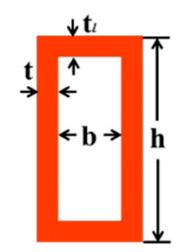

Figure 6. The dimension notations of the hollow section beam.

\subsection{Transformed Section Method}

For the cross section composed of two different materials, such as GFRP and epoxy mortar, the transformed section method was used to analyze the mid-point deformation of the beam. As the Young's modulus and shear modulus of the GFRP materials were used in Equations (1) and (2), the area $(A)$ and moment of inertia $(I)$ of the combined section for beam specimens need to be calculated using the transformed section method.

The elastic modulus ratio of the epoxy resin mortar and GFRP material was defined as $N$, as shown in Equation (7); and the $N$ value was used as the transformed section between different materials.

$$
N=\frac{E_{\text {mortar }}}{E_{G F R P}}
$$

The area and moment of inertia of the combined section in Equations (1) and (2) were defined as $A_{\text {total }}$ and $I_{\text {total }}$, respectively. They can be expressed as follows:

$$
\begin{gathered}
A_{\text {total }}=A_{G F R P}+N A_{\text {mortar }} \\
I_{\text {total }}=I_{G F R P}+N I_{\text {mortar }}
\end{gathered}
$$

where $A_{G F R P}$ and $A_{\text {mortar }}$ are the areas of the GFRP and epoxy mortar in the combined section; $I_{G F R P}$ and $I_{\text {mortar }}$ are the moment of inertias of the GFRP and epoxy mortar in the combined section.

\subsection{Theoretical Analysis of GFRP Deck}

In this study, the GFRP deck member's length-depth ratio $(L / h=90 / 5=18)$ is 18 , which shear deformation contribution can be neglected. The moment of inertia $I_{\text {total }}$, was calculated and shown in Table 7 .

In specimen A (prototype), the results from the Euler beam theory had similar initial stiffness as the experimental results, as shown in Table 8. When specimen AT was subjected to loading, it 
was found that the GFRP deck and inserted GFRP tube were delaminated. The force-displacement relationships in Figure 7 reveal that experimental stiffness of specimen AT is less than theoretical stiffness calculated by the Euler beam theory due to delamination, as shown in Table 8. For specimens ATE1 and ATE2, the absolute errors of the initial stiffness between the experimental and Euler beam theory were less than $3 \%$, as shown in Table 8 .

Table 7. Section properties of double-compartment deck specimens.

\begin{tabular}{cc}
\hline Specimen & Moment of Inertia, $\boldsymbol{I}_{\text {total }}\left[\mathrm{cm}^{\mathbf{4}}\right]$ \\
\hline A & 165.7 \\
AT & 226.1 \\
ATE1 & 236.6 \\
ATE2 & 254.9 \\
\hline
\end{tabular}

As shown in Figure 7, the force-displacement diagrams of the experimental and Euler beam theoretical analysis were close for all GFRP deck members, except specimen AT. As for the initial stiffness of GFRP beam specimen calculated from Timoshenko theory, these were less than those obtained from the experiment; and the absolute errors of the initial stiffness between the experimental and Timoshenko beam theory were between $14 \sim 44 \%$, as shown in Table 8 . For GFRP deck members that has length-depth ratio 18, the initial stiffness obtained from Euler beam theory had better accuracy than that of Timoshenko beam theory.

Table 8. The errors of the stiffness GFRP deck between experiments and theoretical analysis.

\begin{tabular}{|c|c|c|c|c|c|}
\hline Specimen & $\begin{array}{l}\text { Experiment, } \\
K(\mathrm{kN} / \mathrm{cm})\end{array}$ & $\begin{array}{c}\text { Euler, } \\
K(\mathrm{kN} / \mathrm{cm})\end{array}$ & $\begin{array}{l}\text { Absolutely } \\
\text { Error of Euler (\%) }\end{array}$ & $\begin{array}{l}\text { Timoshenko, } \\
\text { K (kN/cm) }\end{array}$ & $\begin{array}{c}\text { Absolutely } \\
\text { Error of Timoshenko (\%) }\end{array}$ \\
\hline $\mathrm{A}$ & 22.39 & 22.9 & 2.2 & 12.7 & 43.2 \\
\hline $\mathrm{AT}$ & 25.70 & 31.25 & 21.6 & 19.74 & 23.2 \\
\hline ATE1 & 33.50 & 32.72 & 2.3 & 28.57 & 14.7 \\
\hline ATE2 & 35.83 & 35.24 & 1.6 & 30.18 & 16.1 \\
\hline
\end{tabular}

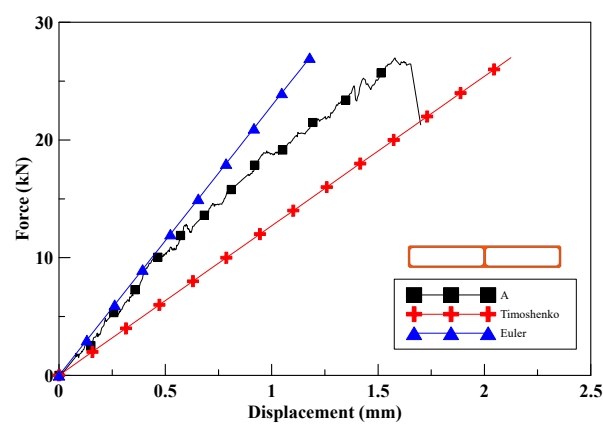

(a) Specimen $\mathrm{A}$

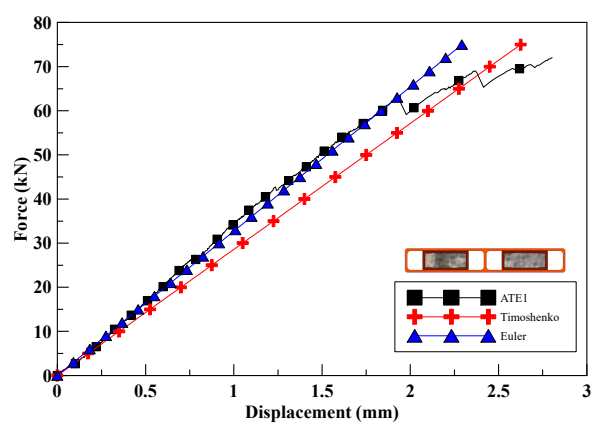

(c) Specimen ATE1

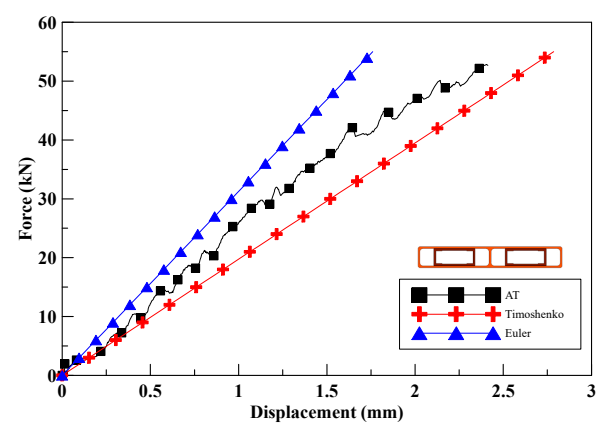

(b) Specimen AT

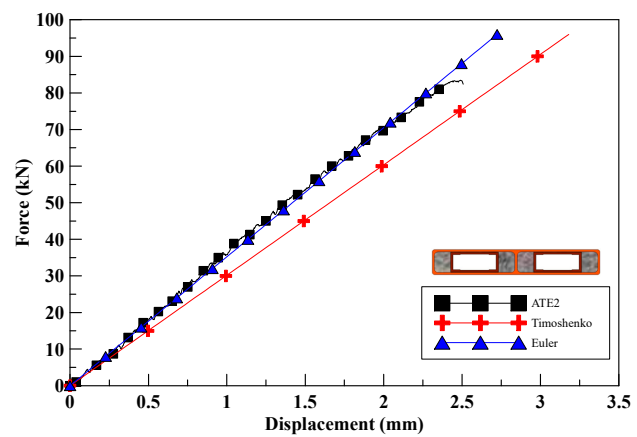

(d) Specimen ATE2

Figure 7. The experimental and analytical force-displacement relationships of GFRP deck specimens. 


\subsection{Theoretical Analysis of GFRP Beam}

In this study, the GFRP beam member's length-depth ratio $(L / h=90 / 7.4=12.16)$ is 12.16 . In Table 9, the shear coefficient $(k)$ and moment of inertia $\left(I_{\text {total }}\right)$ were calculated using Equations $(4)$ and (8), respectively.

Table 9. Section properties of the GFRP beam specimens.

\begin{tabular}{ccc}
\hline Specimen & Shear Coefficient, $\boldsymbol{k}$ & Moment of Inertia, $\boldsymbol{I}_{\text {total }}\left[\mathrm{cm}^{\mathbf{4}}\right]$ \\
\hline B & 0.389 & 171.12 \\
BR & 0.360 & 206.40 \\
BE & 0.447 & 209.18 \\
BRE1 & 0.494 & 221.37 \\
BRE2 & 0.447 & 220.02 \\
\hline
\end{tabular}

The initial stiffness of the specimen B (prototype) is between the stiffness of the Euler and Timoshenko beam theories, as shown in Table 10. As seen in Table 10, the absolute errors of the initial stiffness between the experiments, and Euler and Timoshenko beam theories, were between $0.2 \sim 11 \%$, and $0.4 \sim 17 \%$, respectively. As shown in Figure 8, the experimental force-displacement diagrams of GFRP beam specimens were close to the force-displacement diagrams obtained from Euler and Timoshenko beam theories. We can conclude that GFRP beam members have a length-depth ratio 12.16 , and their behavior is flexural-shear deformation.

Table 10. The errors of the stiffness of GFRP beam between experiments and theoretical analysis.

\begin{tabular}{|c|c|c|c|c|c|}
\hline Specimen & $\begin{array}{l}\text { Experiment, } \\
K(\mathrm{kN} / \mathrm{cm})\end{array}$ & $\begin{array}{c}\text { Euler, } \\
K(\mathrm{kN} / \mathrm{cm})\end{array}$ & $\begin{array}{l}\text { Absolutely } \\
\text { Error of Euler (\%) }\end{array}$ & $\begin{array}{l}\text { Timoshenko, } \\
\text { K (kN/cm) }\end{array}$ & $\begin{array}{c}\text { Absolutely } \\
\text { Error of Timoshenko (\%) }\end{array}$ \\
\hline B & 22.02 & 23.66 & 7.4 & 19.55 & 11.2 \\
\hline BR & 28.93 & 28.54 & 1.35 & 24.03 & 16.9 \\
\hline $\mathrm{BE}$ & 27.94 & 28.92 & 3.5 & 27.82 & 0.43 \\
\hline BRE1 & 34.53 & 30.61 & 11.3 & 29.17 & 15.5 \\
\hline BRE2 & 30.66 & 30.60 & 0.19 & 28.97 & 5.5 \\
\hline
\end{tabular}

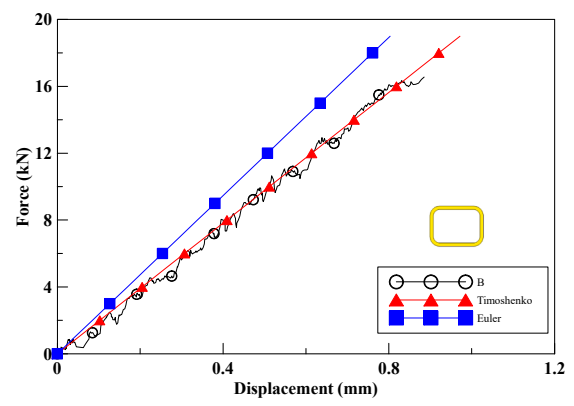

(a) Specimen B

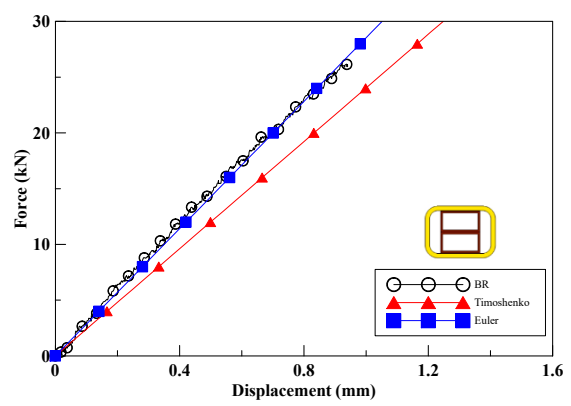

(c) Specimen BR

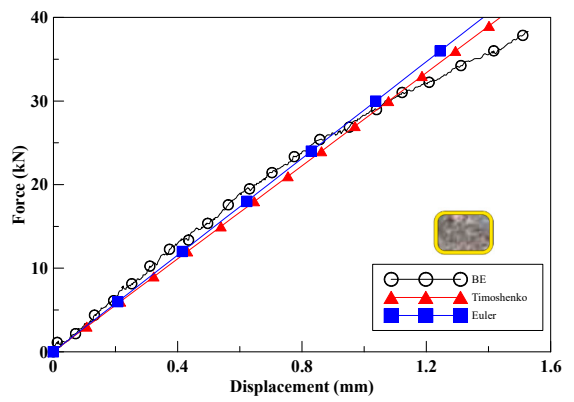

(b) Specimen BE

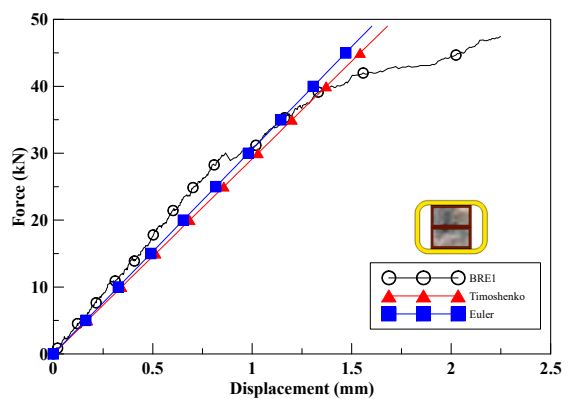

(d) Specimen BRE1

Figure 8. Cont. 


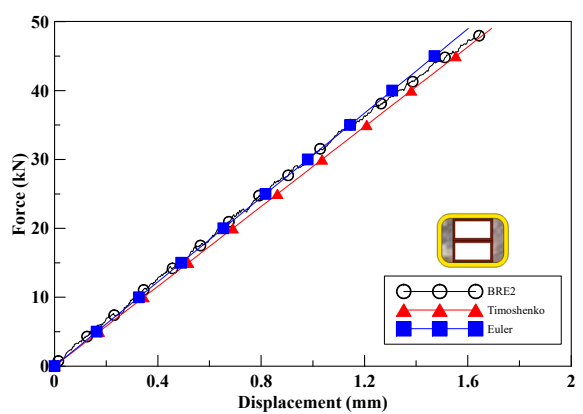

(e) Specimen BRE2

Figure 8. The experimental and analytical force-displacement relationships of GFRP beam specimens.

\section{Conclusions}

Based on the experimental work and theoretical analysis conducted in this study, the following conclusions were drawn.

Firstly, the ultimate force, ultimate displacement, and initial stiffness of deck specimens ATE1 and ATE2 significantly increased in comparison to the prototype specimen A. Similarly, the ultimate force, ultimate displacement, and initial stiffness of beam specimens BR, BE, BRE1 and BRE2 increased in comparison with the prototype specimen B. It can be concluded that inserting a rectangular GFRP tube into the compartments of the GFRP members, and filling the hollow compartments with epoxy resin mortar, can not only improve the stiffness, but also the ultimate strength and corresponding ultimate displacement of the GFRP members.

Secondly, as seen from the three-point bending test results, specimens ATE1 and ATE2, BRE1 and BRE2 have better stiffness performance due to the increase of the moment of inertia of the combined GFRP member.

Thirdly, the Euler and Timoshenko beam theories combined with the transformed section method were used to obtain the force-displacement relationships of the combined GFRP member. For GFRP deck members that have a length-depth ratio of 18, the initial stiffness obtained from Euler beam theory had better accuracy. It can be concluded that the GFRP deck behavior is flexural deformation.

Fourthly, the experimental force-displacement diagrams of GFRP beam specimens were between the force-displacement diagrams obtained from Euler and Timoshenko beam theories. The GFRP beam members have a length-depth ratio of 12.16 , and the behavior is flexural-shear deformation.

Author Contributions: Conceptualization, Y.F.L. and T.H.H.; Methodology, Y.F.L. and F.C.H.; Experiment, F.C.H.; Writing-Original Draft Preparation, T.H.H.; Writing-Review and Editing, Y.F.L.; Supervision, Y.F.L.; Project Administration, Y.F.L.

Funding: This research was funded by National Science Council of Taiwan, under contract No. NSC-100-2221-E-027-086, and the "Research Center of Energy Conservation for New Generation of Residential, Commercial, and Industrial Sectors" from the Ministry of Education (MOE) in Taiwan.

Conflicts of Interest: The authors declare no conflict of interest.

\section{References}

1. Li, Y.F.; Yu, C.C.; Chen, S.Y.; Badjie, S. The carbon footprint calculation of the GFRP pedestrian bridge at Tai-Jiang National Park. Int. Rev. Spat. Plan. Sustain. Dev. 2013, 1, 13-28. [CrossRef]

2. Zhang, C.; Amaduddin, M.; Canning, L. Carbon dioxide evaluation in a typical bridge deck replacement project. Proc. Inst. Civ. Eng. Energy 2011, 164, 183-194. [CrossRef]

3. Hollaway, L.C. A review of the present and future utilization of FRP composites in the civil infrastructure with reference to their important in-service properties. Constr. Build. Mater. 2010, 24, 2419-2445. [CrossRef]

4. Kumar, P.; Chandrashekhara, K.; Nanni, A. structural performance of a FRP bridge deck. Constr. Build. Mater. 2004, 18, 35-47. [CrossRef] 
5. Liu, Z. Testing and Analysis of a Fiber-Reinforced Polymer (FRP) Bridge Deck; Virginia Polytechnic Institute and State University: Blacksburg, VA, USA, 2007.

6. Majumdar, P.K. Strength and Life Prediction of FRP Composite Bridge Deck; Virginia Polytechnic Institute and State University: Blacksburg, VA, USA, 2008.

7. Moon, D.Y.; Zi, G.; Lee, D.H.; Kim, B.M.; Hwang, Y.K. Fatigue behavior of the foam-filled GFRP bridge deck. Compos. Part B 2009, 40, 141-148. [CrossRef]

8. Wu, Z.; Mirmiran, A.; Zhu, Z.; Swanson, J. Flexural behavior of prestressed FRP tubular bridge deck. Compos. Part B 2009, 40, 125-133. [CrossRef]

9. Gautam, B.P.; Matsumoto, T. Shear deformation and interface behavior of concrete-filled CFRP box beams. Compos. Struct. 2009, 89, 20-27. [CrossRef]

10. Kim, H.Y.; Park, K.T.; Jeong, J.; Lee, Y.H.; Hwang, Y.K.; Kim, D. A pultruded GFRP deck panel for temporary structures. Compos. Struct. 2009, 91, 20-30. [CrossRef]

11. Kim, H.Y.; Lee, Y.H.; Lee, S.Y. Ultimate strength of a GFRP deck panel for temporary structures. Compos. Struct. 2011, 93, 528-537. [CrossRef]

12. Hai, N.D.; Mutsuyoshi, H.; Asamoto, S.; Matsui, T. Structural behavior of hybrid FRP composite I-beam. Constr. Build. Mater. 2010, 24, 956-969. [CrossRef]

13. Chen, A.; Davalos, J.F. Strength evaluations of sinusoidal core for FRP sandwich bridge deck panels. Compos. Struct. 2010, 92, 1561-1573. [CrossRef]

14. Fam, A.; Honickman, H. Built-up hybrid composite box girders fabricated and tested in flexure. Eng. Struct. 2010, 32, 1028-1037. [CrossRef]

15. Ji, H.S.; Song, W.; Ma, Z.J. Design, test and field application of a GFRP corrugated-core sandwich bridge. Eng. Struct. 2010, 32, 2814-2824. [CrossRef]

16. Ji, H.S.; Byun, J.K.; Lee, C.S.; Son, B.J.; Ma, Z.J. Structural Performance of Composite Sandwich Bridge Decks with Hybrid GFRP-Steel Core. Compos. Struct. 2011, 93, 430-442. [CrossRef]

17. Lombardi, N.J.; Liu, J. Glass fiber-reinforced polymer/steel hybrid honeycomb sandwich concept for bridge deck applications. Compos. Struct. 2011, 93, 1275-1283. [CrossRef]

18. Zuo, Y.; Mosallam, A.; Xin, H.; Liu, Y.; Hec, J. Flexural performance of a hybrid GFRP-concrete bridge deck with composite T-shaped perforated rib connectors. Compos. Struct. 2018, 194, 263-278. [CrossRef]

19. Li, Y.-F.; Badjie, S.; Chen, W.Y.; Chiu, Y.T. Case study of first all-GFRP pedestrian bridge in Taiwan. Case Stud. Constr. Mater. 2014, 1, 83-95. [CrossRef]

20. ASTM D790. Standard Test Methods for Flexural Properties of Unreinforced and Reinforced Plastics and Electrical Insulating Materials; ASTM: West Conshohocken, PA, USA, 2017.

21. Schniepp, T.J. Design Manual Development for a Hybrid, FRP Double-Web Beam and Characterization of Shear Stiffness in FRP Composite Beams; Virginia Polytechnic and State University: Blacksburg, VA, USA, 2002.

22. Dym, C.L.; Shames, I.H. Solid Mechanics: A Variational Approach; Springer-Verlag: New York, NY, USA, 2013; Volume 99, pp. 187-194, ISBN 978-1-4614-6034-3.

23. Cowper, G.R. The Shear Coefficient in Timoshenko's Beam Theory. J. Appl. Mech. 1996, 33, 335-340. [CrossRef]

(C) 2019 by the authors. Licensee MDPI, Basel, Switzerland. This article is an open access article distributed under the terms and conditions of the Creative Commons Attribution (CC BY) license (http://creativecommons.org/licenses/by/4.0/). 